\title{
AS VIRTUDES DO HEREGE: ENSAIO, MODERNISMO E ESCRITA DA HISTÓRIA EM CASA-GRANDE ESENZALA'
}

\author{
Fernando Nicolazzi \\ f.nicolazzi@hotmail.com
}

"Pour satisfaire pleinement à la loi de l'essai, il faut que 'l'essayeur' s'essaie lui-même"

Jean Starobinski (STAROBINSKI, 1985, p. 191)

\section{GILBERTO FREYRE ENSAÍSTA}

Dizer "Gilberto Freyre ensaísta" é certamente chover no molhado. Afinal, parece fazer parte de uma evidência incontornável o fato de Gilberto desde sempre ter assumido para si este gênero de escrita e, inclusive, fazer dele objeto de uma defesa acirrada, misturando-o entre o discurso abertamente literário e o exclusivamente científico. Entretanto, salvo algumas poucas análises, o tema não foi ainda desenvolvido de maneira mais proveitosa, não apenas para a compreensão da obra do sociólogo, mas, sobretudo, para o entendimento mais vasto das suas implicações para o pensamento social brasileiro e, em particular, para a história da historiografia brasileira.

1 A elaboração deste artigo contou com financiamento da CAPES. 
Alguns comentários sobre a temática podem ser arrolados para se perceber isso. A começar por um artigo mais recente, "Entre o inferno e o paraíso: o ensaio de Gilberto Freyre", publicado por Silvana Moreli Vicente, significativamente em uma revista de estudos linguísticos. A intenção da autora é tentar verificar se o ensaio de Freyre "pode ser incluído no paradigma de um gênero ou forma literária caracterizado pela abertura, fluidez e ambiguidade". A terminologia por ela utilizada, que parece tentar precisar o objeto, não sucede, todavia, a escapar da inconstância conceitual: fala-se em uma "impureza literária horizontal" que contaminaria os diversos escritos do autor de Apipucos, situando sua escrita em um "gênero de intervalo, de transição ou literatura in potentia" que seria o ensaio. Assim, conclui-se que "o espaço textual da casa-grande e da senzala pode ser visto como um mosaico de micronarrativas cujo objetivo seria evocar o universo recuado no tempo dos antepassados" e, assim sendo, "em Casa-grande E Senzala, Freyre encarna o espírito ensaístico ao apresentar, como em fascinante mosaico, uma multiplicidade de perspectivas que mantém o leitor sempre desperto" (VICENTE, 2005, p. 680-685). O tom elogioso ("fascinante mosaico") não esconde o fato fundamental: ao multiplicar as ambiguidades ("impureza literária", "gênero de intervalo", "mosaico de micro-narrativas") a autora nada mais fez do que reafirmar a evidência. É bem verdade que ficou no artigo um indício um pouco mais preciso: o ensaio seria uma forma predominante no pré-modernismo e no modernismo. Sem entrar ainda no mérito da utilização dos termos, percebe-se que tal estudo em nada avançou na discussão sobre os nexos entre texto e contexto. Quais as razões para o mencionado predomínio? Que relações se pode estabelecer entre uma situação política e social (a primeira república), um momento cultural (modernismo) e um gênero discursivo (o ensaio histórico)?

Em outro trabalho, o ensaio de Gilberto é igualmente analisado sob uma perspectiva oriunda dos estudos literários e linguísticos, propriamente de uma "estilística da enunciação". Estudando a construção do estilo de escrita na elaboração de CGES, Vânia de Barros Falcão defende que "Gilberto Freyre produziu um texto científico numa linguagem que se considerou literária. Tal afirmativa, cada vez que é reproduzida, introduz uma nova reflexão sobre a questão do estilo de Freyre, incompreendido por muitos e alvo de diversas críticas, principalmente por que fugia ao cânone que identificava uma obra como sendo científica" (FALCÃO, 2003, p. 180, itálico meu). Sem precisar com maiores detalhes o que constituiria tal cânone, a autora não fornece elementos para se perceber em que medida e como Freyre fugiria a ele, já que é moeda corrente entre os estudiosos ressaltar a porosidade, para 
as primeiras décadas do século $\mathrm{XX}$, entre campo científico e campo literário, e no primeiro mais precisamente, entre as ciências naturais e as sociais. Mas ela recorre à noção de ensaio para reafirmar o lado "alternativo" do escrito freyreano, a partir da definição do gênero dada por Massaud Moisés no seu Dicionário de Termos Literários, de 1974. Assim, segue que "o ensaísta não busca provar ou justificar as suas idéias nem se preocupa com lastreá-las eruditamente"; ele visa antes comover seu leitor do que persuadi-lo (MOISÉS, 1974, p. 177, itálicos meus). Fica a impressão de que há nesse estudo uma grade muito forte que encerra os termos "literário" e "científico", uma dicotomia tal que apenas um gênero tão polivalente quanto impreciso pudesse ocupar o espaço criado no intervalo entre ambos. Mas, no final das contas, a balança parece pesar para um dos lados, e CGES emerge da análise como alternativa à linguagem científica: "aquela linguagem na qual deveriam ser escritas as obras científicas é um sistema fechado e institucionalizado que não se curva facilmente a transformações e às novas possibilidades que surgem a partir de movimentos sociais e culturais" (FALCÃO, 2003, p. 221); o ensaio histórico, por outro lado, escaparia a tal fechamento disciplinar.

Como se vê, o jogo antitético ciência versus literatura parece não avançar muito as discussões, senão por outras razões, ao menos pelo fato de que não se intenta ali definir com rigor o que seja ciência e o que vem a ser literatura, quanto mais o que as distingue tão nitidamente. As imprecisões levam inclusive, em alguns casos, à oposição entre "ensaio literário" e "ensaio sociológico", aquele caracterizado propriamente pela qualidade de "seduzir o leitor" (FONSECA, 2002). Mas estes poucos e recentes exemplos não são regra geral, nem a sua proximidade temporal se constitui como novidade (cf. CORRÊA, 1962, p. 166-176). Há casos em que, por variações diversas, a temática do ensaio é levantada de forma a tornar mais rica e complexa a questão.

É o exemplo do curto (mas repleto de desdobramentos) artigo de Francisco José Rodrigues, premiado em terceiro lugar no concurso promovido pelo Instituto Joaquim Nabuco ao se comemorar os quarenta anos de CGES (RODRIGUES, 1974, p. 233-247). Rodrigues ressalta, para o contexto dos anos 1920 e 30, o anseio intelectual de "redescoberta" do Brasil, salientando duas formas discursivas que preponderaram entre os intelectuais: o "romance nordestino", notadamente o de caráter social ligado à representação de uma determinada realidade regional, e o "ensaio", propriamente de feições sociológicas e históricas. A análise empreendida do ensaio gilbertiano, conquanto parta das relações entre ciência e literatura - "o insólito que realiza de conciliar o científico com o literário” (RODRIGUES, 1974, p. 236) - não se contenta simplesmente 
em permanecer no terreno ambíguo de fronteira, nem se resume a ajuizar um predomínio de um ou outro elemento. Pelo contrário, o autor se ocupa em investigar de que maneira eles contribuem para as características particulares do gênero, indicando o lugar de cada um na obra em questão, partindo do pressuposto de que a confluência entre o literário e o científico não oculta o dado fundamental sobre o livro: este segue "do literário para o científico" (RODRIGUES, 1974, p. 237).

Com efeito, a ambivalência do dado científico é notada, sobretudo, pela dimensão conceitual que Freyre confere a seu escrito. Mesmo reconhecendo o fato do autor jamais ter atribuído à obra de Max Weber uma importância fundamental ao seu trabalho, Rodrigues destaca alguns "tipos-ideais" na construção sociológica do livro; acima de todos, é possível compreender o termo "casa-grande", não apenas como palavra remetendo a um referente extra-discursivo, mas como conceito que objetiva dar inteligibilidade ao real estudado, afinal a noção indica diretamente um sistema social particular com uma série de características próprias ressaltadas pelo autor. ${ }^{2}$ Assim, como artefatos abstratos, "mas construídos a partir do real", como adverte Rodrigues, os conceitos desempenham no texto uma certa função fictícia que, se elaborados segundo uma matriz científica, empurram o texto para longe de uma ciência empirista que enxergaria na linguagem apenas um meio transparente de representação do real. Nesse sentido, o trabalho de conceituação empreendido por Freyre em CGES seria o dado inequívoco que o manteria entre o "real" e o "abstrato", entre a experiência e o discurso, ou, para se falar em termos da empobrecedora dicotomia, entre ciência e literatura. Francisco José Rodrigues dá esse passo de fundamental importância na discussão, embora o seguimento de sua reflexão não aproveite a riqueza teórica dela. Pois para ele, o reconhecimento desse "não-positivismo" de Freyre seria, mesmo que insuficiente por si só, um indício plausível do caráter literário do livro. ${ }^{3} \mathrm{Na}$ continuidade de sua reflexão, o autor considera ainda que a dimensão ensaística do escrito

2 Weber reconhecia o papel constitutivo dos conceitos no saber elaborado pelas ciências humanas, definindo-as como uma "tentativa de organizar teoricamente os fatos por uma construção de conceitos - decompondo os quadros de pensamento assim obtidos graças a um alargamento e a um deslocamento do horizonte da ciência - e a construção de novos conceitos sobre a base assim modificada” (WEBER, 1965, p. 203).

3 "Considere-se que um modelo não-positivista de abordagem sociológica muito facilita a elaboração de uma obra de real valor literário [e] facilmente converte a análise sociológica em obra não só de estilo, mas também de recriação ou até de criação artística sem prejuízo algum da fidelidade que deve ter o cientista à realidade da vida" (RODRIGUES, 1974, p. 241). 
não compromete "a manipulação da prova documental e da pesquisa de campo", o que o colocaria de fato distante do positivismo "à Comte ou à Ranke".

Ou seja, seguindo tal perspectiva, compreende-se o ensaísmo de Freyre como texto fundado em uma observação particular do real, amparada pelo recurso documental de que dispôs o autor. Sem se deter sobre a questão das fontes, Rodrigues avança no uso que Gilberto faz da linguagem, chegando em outro ponto fundamental. Para o comentador, ocorre em CGES um processo de transformação discursiva em que elementos retirados do campo empírico se transformam, no texto, em "símbolos". Segundo sua leitura, “cajueiros e araçazeiros', bem como a 'touceira de bananeira' não são apenas elementos materiais e enumerativos, como seriam, aliás, em uma análise positivista, mas símbolos [...] símbolos sociais ou culturais sobre que se constrói uma fabulação real e não ideal" (RODRIGUES, 1974, p. 242). A aproximação com a fábula introduz na análise a idéia de mito que, não sendo estabelecido a partir de uma crença, desempenha para Freyre a função de convencer o leitor de seus argumentos. Com isso, "o tratamento da realidade, em Casa-grande $\mathcal{E}$ senzala, sofre um constante processo de personificação do abstrato e de abstração simbólica do concreto e individual. Um processo de remodelagem racional da realidade" (RODRIGUES, 1974, p. 243); em outras palavras, Gilberto Freyre sucede em pegar a matéria bruta do real e transformá-la em linguagem, criando a sensação de que há uma continuidade essencial entre o texto e o fora-do-texto, entre a experiência histórica e a história dessa experiência.

Se Francisco José Rodrigues não desenvolveu mais à fundo a discussão, Ricardo Benzaquen de Araújo traduziu de forma ímpar aquele processo de "fabulação do real", ainda que sem redundar nessa terminologia demasiadamente carregada. Para ele, CGES "deixa de ser apenas um livro para transformar-se em uma espécie de casa-grande em miniatura, em uma voz longínqua mas genuína, legítima e metonímica representante daquela experiência que ele próprio analisava, enquanto o nosso autor se converte, até certo ponto, em personagem de si mesmo, como se escrevesse não só um ensaio histórico-sociológico mas também as suas mais íntimas memórias" (ARAÚJO, 2005, p. 187). As consequências teóricas disso desdobram-se em duas linhas convergentes, ambas levantadas por Benzaquen. Essa "sintonia" entre autor e livro, convertida também em simbiose entre a escrita e aquilo sobre o que se escreve funcionam na economia do texto de forma a legitimar o registro do passado ali proposto. Por um lado, essa sintonia parece produzir efeitos 
no autor de forma a criar uma condição de naturalidade e familiaridade, isto é, como se ele, reconstituindo aquela experiência histórica, pudesse ele mesmo "experienciá-la" no e através do seu texto. Daí, segundo o perspicaz comentador, explica-se o tom de "sentimentalismo" da escrita gilbertiana, definida então como uma espécie de "segunda ingenuidade". Todo o caráter personalista e confessional de que se reveste o livro, dessa maneira, não se deve apenas a um egocentrismo exacerbado do autor, mas funciona, inclusive, como fator para a sua legitimidade. A análise da feição marcadamente memorialista que Gilberto conferiu ao seu escrito comprova isso, a partir do argumento de que a "confessional ingenuidade" ali presente pode ser entendida como uma estratégia discursiva para legitimar a representação da história.

Pois, e este é o outro lado em que se desdobra a questão, a sintonia autor-obra produz o efeito mencionado de uma simbiose entre experiência e linguagem, como se entre elas houvesse uma plena adequação, garantindo, com isso, a validade da representação proposta. Benzaquen fala em termos de uma "autenticidade" conferida pelo autor ao seu relato, dada a proximidade criada no texto entre sujeito e objeto: Freyre fala do passado nacional como um projeção equivalente à sua própria vivência; a experiência pessoal do eu estando intimamente ligada à experiência coletiva do nós. Afinal, tratava-se, como se sabe, da história íntima dos "nossos avós". Porém, e esse é o fato que cabe ressaltar, a fundamentação do relato é também pautada por critérios que transcendem a simples intimidade que o texto cria. Benzaquen sugere, então, que “o método introspectivo' praticado por Gilberto parece harmonizar-se muito bem com a ênfase dada pela Etnologia à idéia de trabalho de campo, dimensão empática e biográfica da atividade etnográfica, dando assim a impressão de adicionar uma sanção científica à sua ascendência literária” (ARAÚJO, 2005, p. 189). Dessa maneira, a experiência da viagem e o trabalho de memória que se desdobram no livro de Freyre, estabelecendo a posição importante do autor no texto, seguem amparadas por uma pesquisa documental que não é realizada segundo um cuidado crítico mais detido (NICOLAZZI, 2008, p. 222-304). ${ }^{4}$ O corpus de fontes escolhido por Freyre tem, em grande parte, este mesmo tom de intimidade que permite a ele a proximidade diante de seu objeto, o que, para Ricardo Benzaquen, auxilia na tarefa de dotar o texto daquela "autenticidade" que garante

4 Benzaquen menciona, em especial, a "aparente" ingenuidade de Freyre no trato de documentos inquisitorais, onde as relações de poder que produzem esse tipo de documento não são jamais levadas em conta pelo sociólogo (ARAÚJO, 2005, p. 191, n. 63). 
a legitimidade de sua representação do passado. Dessa maneira, ainda segundo o analista, o princípio de veracidade subjacente ao livro é bastante particular: "lidamos aqui com uma verdade que, quando se expressa, o faz como um fim em si mesmo, imediato e supostamente irrefreável, obedecendo a necessidades interiores capazes de desencadear emoções de tal ordem que só podem ser reveladas a diários secretos, 'corajosas' autobiografias, ou ao sagrado e 'redentor' patrocínio da Inquisição". A "autenticidade" é, pois, um "motivo retórico" capaz de fazer seu leitor crer naquele que relata tal história, já que ela assume para si todas as feições de um "impulso de natureza confessional" (ARAÚJO, 2005, p. 192; cf. VENTURA, 2001/2, p. 212-223).

Todas as considerações até aqui arroladas permitem retornar com elementos teóricos mais ricos para a apreensão do ensaísmo histórico em CGES. Ricardo Benzaquen, o comentador mais lúcido da escrita freyreana, avançou nas suas considerações até o momento de tratar o ensaio, do ponto de vista teórico, pelo seu inacabamento, pelo seu caráter de obra aberta. Esse sentido de análise não será aqui retomado. A atenção será voltada mais precisamente para as relações entre prática historiográfica e escrita ensaística, segundo o panorama contextual acima elaborado. Se a leitura aqui esboçada dos textos de Benzaquen e Rodrigues está minimamente de acordo com as pretensões dos dois autores, então é possível perceber duas perspectivas diferenciadas de estudo. A primeira, exposta no texto premiado pela Fundação Joaquim Nabuco, retomando as constantes críticas de Freyre ao cientificismo exacerbado, procura buscar no livro a literatura por trás das aparências de ciência que a pesquisa sociológica do autor empreendeu; a segunda, por outro lado, intenta ver nas suas qualidades literárias os mecanismos de legitimação do texto enquanto um saber "cientificamente" conduzido. As considerações finais do Guerra e paz, de Ricardo Benzaquen, parecem indicar essa outra via de análise, muito mais próxima das pretensões deste texto. Dessa maneira, a pergunta sobre o ensaio estaria aqui mais ligada aos seus princípios de legitimação do que às suas disposições estéticas.

\section{CASA-GRANDE E SENZALA: ENSAIO HISTÓRICO E MODERNISMO}

Se, como quer Eduardo Portella, o ensaio enquanto gênero literário goza de vida longa nos trópicos, é inegável que as primeiras décadas do século XX marcaram um momento de culminância da variedade propriamente histórica do gênero, contexto em que o anseio por se 
produzir sínteses sociologicamente embasadas e novos modelos de interpretação do passado se mostrava bastante intenso (PORTELLA, 200o). Período que se costuma chamar de "redescoberta do Brasil" e de "gênese do Brasil moderno", ele responde também, mesmo que vagamente, pelo uso do termo "modernismo", que, na sua inconstância e, por isso, inerente imprecisão, pode servir para conduzir esta reflexão (CANDIDO, 1983; 200o). O caminho já se encontra, por exemplo, no breve livro sobre Nelson Werneck Sodré, de André Moysés Gaio, tendo por título Modernismo e ensaio histórico (GAIO, 2004). Não obstante, a idéia surge, ao se estudar a obra de Gilberto Freyre, desde a leitura da tese de Ricardo Benzaquen de Araújo, que semeou a indagação quando levantou o problema das relações entre ciências sociais e modernismo no Brasil dos anos 1920-30 (ARAÚJO, 2005, p. 17-22).5

Não é de todo exagero conferir a singularidade do ensaio histórico durante a primeira república à ascensão do modernismo, o qual pode aqui ser encarado em dois matizes que definem ordens distintas de desenvolvimento do ensaísmo. Num primeiro momento, a noção de modernismo pode ser referida ao "bando de idéias" novas de que falava Sílvio Romero e que José Veríssimo detalhou em seu artigo sobre o tema publicado na Revista do Brasil em 1916. Nesse sentido, o modernismo aqui se refere à chamada matriz cientificista de pensamento, compreendendo "o positivismo comtista, o transformismo darwinista, o evolucionismo spenceriano, o intellectualismo de Taine e Renan e quejandas correntes de pensamento, que influindo na literatura deviam pôr termo ao dominio exclusivo do Romantismo", além do contexto de efervescência política que marcou o fim do império no Brasil. O período de sua absorção pelos letrados brasileiros data do último quartel do século XIX, caracterizando a revolta contra a geração precedente que marcou os intelectuais de 1870 . Para Veríssimo, o fato mostrava, nos trópicos especialmente, uma "maior liberdade espiritual [e um] mais vivo espirito critico" (VERÍSSIMO, 1916, p. 43-44).

O "movimento modernista" ou o "pensamento moderno" estariam,

5 Ressalte-se que o autor mesmo reconhece ter se desviado, por uma série de razões, dessa intenção primeira. Esta seção, por sua vez, não pretende realizar aquilo que supostamente "ficou por fazer" no trabalho de Banzaquen. Não se trata aqui de investigar detidamente as relações entre ciências sociais e modernismo no Brasil, mas sim usar tal noção (modernismo) de forma a tentar perceber a maneira bem particular pela qual Freyre se relacionou com as vanguardas intelectuais do século XX, e, a partir daí, tentar apreender as singularidades do "seu" ensaísmo histórico. Ver ainda, sobre as relações entre historiografia e modernismo, considerando este limitado à vanguarda literária, o trabalho pioneiro de José Roberto do Amaral Lapa (LAPA, 1981, p. 79-88). 
assim, ligados à chamada Escola de Recife, primeiramente com um precursor como Tobias Barreto e, em seguida, com seu discípulo mais notório e polêmico, Sílvio Romero. Se na história e na crítica literárias Romero despontou como um dos grandes nomes dessa geração, Veríssimo reconhece em Capistrano de Abreu um autor que soube conciliar as inovações no plano do pensamento com a escrita da história propriamente dita. Para ele, a tese sobre o descobrimento do Brasil defendida pelo historiador em 1883, almejando o ingresso no Colégio Pedro II, era sinal inequívoco de inspiração do evolucionismo spenceriano. Assim, seja no plano literário, com o aparecimento, por exemplo, dos romances naturalistas, seja no plano sócio-histórico, com o desenvolvimento da crítica e da filosofia, o "modernismo", tal como denotado por José Veríssimo, marcou um deslocamento considerável na maneira como se pensava e como se escrevia sobre a história pátria. Esse deslocamento criou as condições de possibilidade para autores como Euclides da Cunha, Oliveira Vianna e Manoel Bomfim escreverem seus ensaios.

Por outro lado, no transcorrer do século XX, a noção de modernismo, por razões que não competem aqui esclarecer, passou a definir um contexto cultural bastante mais específico, notadamente ligado à Semana de Arte Moderna e ao movimento de caráter predominantemente estético (num primeiro momento) despontado na região sudeste. A revolta contra determinadas tradições literárias e contra um cânone intelectual já estabelecido, sem dúvida, contribuiu para criar condições para uma forma distinta de escrita, seja no âmbito literário, seja no plano das ciências sociais. Alguns textos-manifestos publicados no primeiro momento do movimento, a chamada "fase heróica", ${ }^{6}$ indicam o teor da ruptura, como se pode notar no "Prefácio interessantíssimo" que abre o Paulicéia desvairada, de 1922, e o texto escrito entre abril e maio do mesmo ano, alegadamente uma resposta aos efeitos produzidos pela Semana ocorrida meses antes, "A escrava que não é Isaura (discurso sobre algumas tendências da poesia modernista)", ambos da pena de Mário de Andrade (ANDRADE, 1972, 1960). Os esforços para a reformulação das bases da linguagem poética são uma das questões mais visíveis colocadas pelo contexto, normalmente encaradas como um deslocamento das fronteiras entre o popular e o erudito nas práticas culturais. O "hermetismo" das

6 A definição, que separa a "fase heróica", entre 1917 e 1928, e o contexto de maior politização nos anos 1930, consta no livro João Luiz Lafetá (LAFETÁ, 1974; cf. também MORAES, 1988). 
tradições cultas passa a ser repensado, embora, como Mário de Andrade sugere, dentro de limites mais ou menos estabelecidos. Sobre isso, advertia o escritor: "não quero porém significar com isso que os poemas devam ser tão chãos que o caipira de Xiririca possa compreende-los tanto como o civilizado que conheça psicologia, estética e a evolução histórica da poesia" (ANDRADE, 196o, p. 3).

O questionamento não visava, dessa maneira, a elisão das diferenças, mas certamente deu ao uso da linguagem uma função um tanto mais prática e cotidiana. Nicolau Sevcenko já apontou o alcance das modificações da linguagem (no sentido largo de códigos culturais) no ambiente modernista brasileiro, alegando que durante a década de 1920 era possível perceber uma "transformação de uma cultura baseada no discurso e na fala, ou seja, no papel preeminente que é simbolicamente atribuído à palavra, em uma cultura que se apóia, sobretudo, no papel primordial que é simbolicamente transferido à ação pura" (SEVCENKO, 1993, p. 78). Essa superação da métrica parnasiana e da retórica bacharelesca criou condições para a criação de um novo espaço não só na poesia, menos ornamental e mais prática, mas também no romance e no âmbito ensaístico, como normalmente se nota em autores como Paulo Prado e Sérgio Buarque de Holanda, diretamente envolvidos com o movimento. ${ }^{7}$

É, portanto, de acordo com essas duas perspectivas de definição da idéia modernista que se pode apreender as relações entre ensaio histórico e modernismo, o termo "pré-modernismo", pelo menos da maneira como estudado por André Moysés Gaio (e não apenas por ele), não sendo aqui mais do que uma variação até certo ponto imprecisa, já que fundada em um reconhecido anacronismo: o período em questão apenas teria seu significado estabelecido se colocado, paradoxalmente, diante do contexto imediatamente posterior. Com isso, o lugar de Gilberto Freyre pode ser melhor perscrutado, uma vez que a relação do sociólogo com o "modernismo" deve tanto ser pensada como decorrente daquele "bando de idéias novas" exaltado por Romero e aqui discutido a partir do texto de Veríssimo, quanto articulada, de forma um tanto particular, com as

7 José Roberto do Amaral Lapa oferece um raciocínio curioso: para ele, enquanto a obra de 1936 de Sérgio era, de fato, uma das renovadoras da historiografia brasileira, o Retrato do Brasil não era por ele considerado propriamente um livro de história, mas sim um livro para a história do Brasil. É um juízo curioso, ainda que não totalmente equivocado, pois, qualquer pessoa que se proponha a ler as duas obras notará no Retrato um recurso documental muito mais constante do que no Raízes, que raramente embasa seus argumentos com o lastro de fontes especificadas (LAPA, 1981, p. 85). 
inovações estéticas trazidas pelo movimento na década de 1920, de que Mario de Andrade foi um dos promotores.

Maria Lúcia Pallares-Burke já traçou o percurso da vocação ensaísta de Gilberto, mostrando como a "descoberta do gênero" lhe abriu portas para o desenvolvimento de uma prosa histórica singular, descoberta ocorrida quando de seus estudos feitos em Baylor, nos Estados Unidos. Freyre frequentou o curso de seu grande mestre naquela instituição, Andrew Joseph Armstrong, professor de literatura que ofereceu uma disciplina sobre os ensaístas ingleses. Fora a oportunidade para Freyre se familiarizar com aquela tradição característica dos periódicos ingleses do século XVIII. O tom coloquial desse tipo de escrita, sua distância aberta do hermetismo erudito, aliado a uma concepção não dogmática de relação com a verdade, cativou o estudante, já que lhe possibilitava jogar com inúmeras variantes disponíveis. "Tendo tomado contato com os ensaístas britânicos numa época em que esse gênero ainda não fora associado ao trivial, superficial, subjetivo, anedótico e inconsistente, Freyre iria considerá-lo um gênero literário respeitável - um 'gênero tão nobre', como disse - e extremamente apropriado para expressar a complexidade de tudo o que é humano" (PALLARES-BURKE, 2005, p. 64-65). Essa mesma tradição, ainda segundo a autora, teria marcado no jovem sociólogo o gosto pelo detalhe do cotidiano, pelo "significado profundo dos pequenos eventos e incidentes diários na vida da sociedade e do indivíduo" (PALLARES-BURKE, 2002, p. 829).

A formação no estrangeiro, onde também teve a oportunidade de entrar em contato direto com vanguardas norte-americanas e européias, sem ter que passar pelo filtro paulista, como ocorrera com seu "rival" Joaquim Inojosa, foi decisiva para delinear os contornos da escrita que havia algum tempo Gilberto procurava. ${ }^{8}$ Ele estava, por assim dizer, em pé de igualdade com os autores do sudeste. De fato, sabe-se que em Paris ele teria se encontrado com Tarsila do Amaral, Victor Brecheret e Oswald de Andrade. Talvez por isso, tendo visto in loco algumas das inovações que os brasileiros queriam fazer assimilar no ambiente

8 Alguns autores reconhecem o interesse de Freyre pelas tendências imagistas da poesia de língua inglesa (new poetry), com nomes como Ezra Pound e Amy Lowell, de quem ele foi amigo particular e com quem trocou correspondência por algum tempo. Segundo Nathan Zach, a despeito da curta duração do movimento, seu impacto teria sido semelhante, no ambiente anglo-saxão, ao que o futurismo e o expressionismo foram na Europa. Das suas características gerais, destacam-se a defesa de uma linguagem mais simples e coloquial, e um relacionamento mais direto com os objetos de representação (ZACH, 1976, p. 228-242). Para as relações de Freyre com o movimento, ver FALCÃO, 2003. 
tropical, no seu retorno tenha encarado já com certa fadiga o "barulho" que se fazia em São Paulo. Para ele, em 1923, "é bom estar a gente longe dos roncos daqueles 'modernistas' daquém e dalém-mar mas que já não parecem ter o que dar a ninguém - nem mesmo aos adolescentes mais adolescentes. A não ser ruído. Escândalo. Sensação" (FREYRE, 1975, p. 132). Chega inclusive a colocar reservas a um nome como o de Mário de Andrade, considerando-o, apesar dele ter sido um dos "bons modernistas", um tanto artificial para o seu gosto. Ainda que não tão publicamente, a relação entre eles foi sempre pautada por essa distância pessoal. Mário, por sua vez, chegou a anotar em seu exemplar de CGES críticas à falta de método de Freyre e, além de tudo, achava que o livro pecou no quesito fundamental do conhecimento histórico: "carece dar provas"; na defesa feita do negro, Gilberto "defendeu e não provou nada" (citado em DIMAS, 2002, p. 868). O autor de Macunaíma que, por meio da intervenção do poeta Manuel Bandeira, chegou e pedir sugestões para Freyre na elaboração do romance, embora reconhecesse as qualidades do ensaio, parece não ter entrado para o grupo dos fãs incondicionais do sociólogo. Um desses, aliás, lia as peripécias do herói sem nenhum caráter como quem lê mais um "arranjo de filólogo erudito do que um instrumento de comunicação oral ou escrito” (José Lins do Rêgo, citado em CASTELLO, 1961, p. 99).

De qualquer modo, a relação de Freyre com o modernismo paulista não é o grande ensejo desta seção (cf. sobre isso, AZEVÊDO, 1984; D'ANDREA, 1992). Interessa aqui apenas mencionar duas maneiras pelas quais Gilberto dá a impressão de ter lidado com o contexto aqui levantado. João Cezar de Castro Rocha lembra que "Freyre parece sugerir que a própria escrita de Casa-grande $\mathcal{E}$ senzala representaria uma espécie de acerto de contas com essa cena de seu período de formação" (ROCHA, 2001, 190); não é demais pensar que se tratava igualmente de uma espécie de prestação de contas consigo mesmo, no anseio de "encontrar seu lugar" naquele ambiente que lhe parecia no mais das vezes hostil, quando não simplesmente artificial.

O modernismo suigeneris de Gilberto Freyrenormalmenteéencarado a partir do coloquialismo de sua linguagem, bastante próxima do campo da oralidade, o que visava conscientemente diluir a distância entre o popular e o erudito, o oral e o escrito ou, quando muito, a diferença entre a fala branca da casa-grande com a fala "colorida" dos pardos e negros. Originado desde os tempos coloniais, Freyre reconhece na história do Brasil o "antagonismo" de linguagem entre os três elementos formadores do povo brasileiro, um "vicio que só hoje, e atravez dos romancistas e poetas mais novos vae sendo corrigido e attenuado: o vacuo enorme entre 
a lingua escrita e a lingua falada". Entre esses "novos" escritores, o autor, pelo menos na primeira edição do livro, elenca nomes tais como Manuel Bandeira, Mário de Andrade, Jorge Amado, Yan de Almeida Prado, Oswald de Andrade, Carlos Drummond, Murilo Mendes, José Lins do Rego entre outros. Em seguida acrescenta uma passagem bastante conhecida: "entre o português dos bachareis e doutores, quasi sempre propensos ao purismo, ao preciosismo e ao classicismo, e o português do povo, do exescravo, do menino, do analphabeto, do matuto, do sertanejo" (FREYRE, 1933, p. 176-177). ${ }^{9}$ Sabe-se o papel preponderante dos negros escravos, sobretudo das mães negras e mucamas, atribuído por Freyre no sentido das modificações na linguagem falada no Brasil. Elas teriam, no contato direto com os meninos e sinhazinhas, amolecido o português "duro" do reino, aqui ensinado segundo as "boas normas" gramaticais pelos padres jesuítas. A negra que amolecia a comida das crianças também amolecia a linguagem falada, fazendo as palavras perderem a rigidez até o limite de se "desmancharem" na boca dos indivíduos. Quanto a isso, inclusive, Ricardo Benzaquen atribuiu a Freyre uma "inclinação anti-retórica" e uma tentativa de fortalecer os laços com a dimensão popular da sociedade brasileira, o que, segundo o autor, não teria se dado plenamente devido à reivindicação de sua ascendência aristocrática (ARAÚJO, 2005, p. 184185).

Freyre foi defensor ferrenho dessa linguagem mais popular e corriqueira, a ponto de fazer de seu livro um elemento importante no projeto que se pode considerar como de abrasileiramento da língua portuguesa. A maneira como ele escrevia tinha a nítida intenção de apresentar isso. Essa era uma das grandes diferenças suas em relação ao Macunaíma do Mário de Andrade, como ele diria mais tarde sobre a escrita de CGES: "em vez de arrevesado jargão ou de elegância, da chamada acadêmica, palavras, na sua maioria, ao alcance do leitor comum; e várias delas rudes, além de inacadêmicas. Mais do que isto: um português salpicado de africanismos, de indianismos, de barbarismos, alguns ousados, embora sem a preocupação de criar o autor língua literária brasileiramente nova, como foi a de Mário de Andrade..." (FREYRE, 2002, p. 706). Note-se que tal definição vem corroborar o argumento, levantado

9 Tais nomes desaparecem na edição "definitiva” do livro. Não pude investigar a edição precisa em que os nomes foram retirados, o que seria bastante significativo da relação do autor com a tradição modernista. A edição crítica do livro, embora aponte as supressões e acréscimos, não realizou um trabalho mais pormenorizado no sentido de precisar as datas das modificações, o que poderia elucidar diversos aspectos na história do livro. 
por Pallares-Burke e aqui trabalhado, sobre a apropriação por parte de Freyre de alguns elementos da tradição ensaística inglesa. Mais do que isso, essa vocação "popular" assumida pelo sociólogo, a despeito de qualquer ambiguidade de suas posições políticas, se insere também como fator importante nos dilemas trazidos pelo modernismo, pelo menos na sua segunda fase, quando as preocupações de ordem estética cedem lugar à inquietação quanto à função social da literatura e da linguagem. Nesse sentido, a literatura regional dos anos trinta seria o exemplo cabal dessa junção da vanguarda estética com as questões sociais já avançadas desde a geração naturalista. Como colocou João Luiz Lafetá, “o romance social e a poesia participante, que então surgiram, são formas em que o conflito procurou resolver-se adotando soluções híbridas, incorporando conquistas da vanguarda e reativando velhos esquemas de representação da realidade" (LAFETÁ, 1974, p. 156).

Enfim, o mérito maior de Freyre na feitura de seu ensaio parece que não foi tanto oferecer uma via alternativa ao modernismo do sudeste, através de uma perspectiva regionalista nordestina que procurava contrapor-se ao cosmopolitismo paulista, com todas as consequências disso resultantes, mas sim o de ter tentado oferecer uma resposta convincente ao naturalismo sociológico, pelo menos à forma de escrita de forte teor cientificista, marcada pela distância e pela dicotomia entre linguagem de ciência e linguagem cotidiana, como é o caso d'Os sertões, de Euclides da Cunha (NICOLAZZI, 2010). Há uma passagem em seu diário, datando de 1923, ou seja, em plena efervescência modernista, que sugere esse argumento. Comentando a obra de Mário Sette, escritor pernambucano que, segundo Freyre, abusava da cor local, sugere que o romance, enquanto gênero literário, não necessita de tantos abusos de estilo; bastaria apenas narrar a experiência como tal: "entretanto, falta a grande parte da nossa literatura - ou quase-literatura? - para ser regionalista, sem caipirismo, uma língua como que tropicalmente brasileira que não deixe nunca de ser portuguesa, como língua literária, para tornar-se subportuguesa, de tão oral”. E continua ele, advertindo que, "através dessa língua, se afirmaria entre nós, não só no ensaio gênero tão nobre - como na ficção e no teatro, uma maior tendência, da parte da nossa literatura, para exprimir um sentido social e, ao mesmo tempo, humano, do drama que vem sendo vivido pelo Brasil de modo regionalmente diverso, embora sempre, em essência, brasileiro" (FREYRE, 1975, p. 130).

Assim como o romance social regionalista, o ensaio históricosociológico seria uma forma privilegiada para representar o país, não no sentido da descrição ufanista de suas paisagens e de seu povo, à 
maneira de certo romantismo tardio que ainda perambulava pelo século XX, mas como representação que conduz à tarefa de solucionar os impasses sociais vividos pela nação. Cabe notar a ambivalência do juízo de Freyre. Ao mesmo tempo em que defende uma literatura documental próxima das tendências naturalistas do século XIX (narrar a experiência como tal, sem artifícios de estilo), ele incorpora aí parte das inovações propostas pelas vanguardas estéticas, no sentido de oferecer uma linguagem mais palatável para o público geral. Flora Süssekind já mencionou a permanência do naturalismo na literatura brasileira, que atribuía a principal característica dessa tendência à negação da ficcionalidade do texto literário, como se as palavras fossem apenas um meio transparente de representação. Freyre, por sua vez, ao reconhecer o papel fundamental da língua na tarefa de "exprimir um sentido social e humano" da nação, visava querer se distinguir profundamente da matriz naturalista (SÜSSEKIND, 1984)..$^{\circ}$

É verdade que boa parte das ferramentas conceituais de sua interpretação, como a ênfase numa sociologia genética e o papel determinante do meio na sua análise, ainda remetem a uma perspectiva biologizante ou, pelo menos, como já mostrou Luiz Costa Lima, a uma contradição de fundo entre culturalismo e naturalismo (LIMA, 1989). Mas não deixa de ser importante também a ênfase por ele colocada na recusa do puro e simples cientificismo, cuja tradição em Pernambuco remontava à faculdade de direito do Recife, assim como ele procurava se manter em igual distância daquilo que chamou de "literatice dos chamados 'beletristas"”. Sua atuação como professor de sociologia, não obstante efêmera, contribuiu para essa posição. A cadeira de sociologia proposta por Estácio Coimbra na Escola Normal do Recife teve Gilberto Freyre como fundador e professor, entre 1929 e 1930, antes do seu exílio. Sobre isso, ele escreveu em seu diário: "o que farei será tentar fundar uma cátedra de Sociologia com orientação científica, base antropológica e acompanhada de pesquisa de campo". Colocando as seguintes ressalvas: "mas tendo cuidado com o cientificismo, a que venho me referindo em vários artigos como um mal a ser evitado em nossa cultura. Portanto: conservando pontes entre a Sociologia ou a Antropologia Social científica e a humanística, filosófica e até literária. Pois precisamos não confundir a literatura dos humanistas com a literatice dos chamados "beletristas". Ainda assim, confidenciou ser a prática docente algo pouco prazeroso, que fazia, senão por outras coisas (de ordem social e econômica), pelas

10 Entendo aqui o naturalismo menos como uma "escola literária" do que como uma matriz de representação do real. Sobre isso, ver BLANCKAERT, 2000; 2004. 
possibilidades de experimentação que ela propiciava. Como ele escreveu, "a cátedra de Sociologia não me entusiasma senão pelo que nela há de experimental. Ou de plástico, flexível, assistemático. Aliás a função didática não me atrai a não ser como curta experiência" (FREYRE, 1975, p. 219; cf. ainda, MEUCCI, 2006).

Enfim, tal como era característico do modernismo, sua postura tateante, experimentalista, Freyre também ensaiou uma maneira própria de escrita, jogando com as variantes que o contexto lhe disponibilizava, mas arranjando-as de uma maneira particular, no anseio de conferir ao seu escrito uma espécie de marca individual. Ele uma vez comparou o estilo com o ritmo de respiração de um autor, por ser algo deveras pessoal. Nesse sentido, em seu ensaio conseguiu propor uma via distinta da assepsia naturalista, da maneira como Émile Zola a imaginou e, por aqui, Euclides da Cunha a praticou, ao mesmo tempo em que não assumiu por completo as deliberações da vanguarda modernista (NICOLAZZI, 2011). Além disso, o gênero foi importante, sobretudo, porque lhe permitiu um exercício controlado de subjetividade, um jeito de ensaiar-se a si mesmo através da linguagem, como indica a epígrafe acima colocada. Escrever da maneira cotidiana e íntima como se estivesse falando a mesma língua falada pelos personagens que narra, era também uma prática de empatia, espécie de postura metodológica essencial em sua pesquisa. Freyre se colocava, dessa maneira, diante de seu objeto, e não distante dele, como Euclides a todo momento tentou fazer (NICOLAZZI, 2008, p. 154-221). É verdade, como afirmou Benzaquen, que isso conferia ao relato toda uma autenticidade que o legitimava. E isso trazia, ao mesmo tempo, o autor para o primeiro plano; ele que jamais tentava se apagar ao escrever história, assumindo plenamente a função do historiador defendida por Jules Michelet e que ele próprio ressaltava.

\section{GILBERTO FREYRE: O HISTORIADOR COMO ENSAÍSTA}

O parecer é de um historiador célébre: "essayiste oui; mais historien en sus". Nadando na corrente aberta pelo Os sertões, como reconhece Fernand Braudel, a singularidade do ensaísmo de Freyre estava no uso da sua rica documentação - "o mais lúcido e o mais rico, em todo caso, o mais documentado”. Gilberto Freyre historiador era ainda privilegiado, já que repleto de lembranças pessoais e familiares, "apoiando-se fortemente sobre o conhecimento de seu Brasil à lui”. Pode-se pensar (é certo que o francês Braudel não chegaria a tanto!) numa espécie de Michelet dos trópicos: a história nasce dele mesmo; o Brasil é ele, ele 
é sua história. "Tão objetivo que seja o pensamento de Gilberto Freyre, ele é constantemente iluminado de dentro. Ele se situa de bom grado sobre o plano da lembrança e da confidência" (BRAUDEL, 2002, 1077; sobre Michelet e seu moi-histoire, cf. HARTOG, 2005). Essa projeção de si para o âmbito geral da nação, Freyre já havia sugerido em passagem de seu diário do ano de 1918, quando não tinha ainda sequer vinte anos de idade. Comentando um texto de Thomas Carlyle, autor que se dedicou, na primeira metade do século XIX, à escrita de caráter biográfico, Gilberto refletiu sobre a existência humana analisada pela ciência e pela arte: "daí poder dizer-se que, em essência, a História, a Antropologia e, paradoxalmente, a própria Sociologia, não é senão a reunião de inúmeras biografias. Pelo menos não deveria a História ser senão isto: a essência de inúmeras biografias" (FREYRE, 1975, p. 27). É claro que se tratava de uma passagem escrita na juventude, anterior ao contato mais intenso com os procedimentos historiográficos possibilitados na sua entrada na Universidade de Columbia na década de 1920, mas ela ainda assim é significativa de um procedimento que, de forma geral, vai se manter ainda na feitura do CGESS: o caminho que segue do particular (Freyre) ao todo (nação).

"Gilberto Freyre historiador". Menos que a definição de um rótulo disciplinar, a expressão faz pensar no lugar ocupado pelo sábio de Apipucos na tradição historiográfica brasileira. É evidente, como vem sendo discutido até aqui, que esse lugar é determinado pelo gênero de escrita por ele assumido, pelo menos para o livro que serve de objeto a este artigo. Mas algumas colocações merecem ser feitas também para caracterizar melhor a "operação historiográfica" gilbertiana. O primeiro dado a ser mencionado é algo que usualmente é pouco levantado. Embora seja por demais repetida a importante relação mantida com Franz Boas durante sua estada em Nova Iorque, cabe notar que na escolha de Freyre pela Universidade de Columbia teve peso igualmente importante o professor William Shepherd, o orientador de seus trabalhos e, em certa medida, iniciador da sua formação no campo da prática historiográfica (PALLARES-BURKE, 2005, p. 299-300). Shepherd era um especialista em história da América Latina, sendo considerado um dos promotores desse campo de estudo nos Estados Unidos. Além disso, a universidade era o centro de um processo de renovação dos estudos históricos no país, conhecido como new history, que contava, entre outros, com Harry Elmer Barnes, Charles Austin Beard, James Harvey Robinson, Frederick Jackson Turner, Franklin Henry Giddings além do próprio Boas (TUNA, 2003, p. 83 e ss.; cf. NOVICK, 1998, p. 86 e ss.). 
Segundo Barnes, esses autores “representavam, inquestionavelmente, o mais avançado e progressista grupo de historiadores jamais reunido em qualquer instituição de ensino superior" (BARNES, 1972b, p. 29-30). Promotores de uma visão renovada do processo histórico, defendiam uma relação intensa com outras disciplinas, entre elas a antropologia, no caso, a de Boas ("the real science of anthropology"), e sua perspectiva voltada para os dados da cultura. Afinal, como ressalta o autor, a civilização era um fato e um processo cultural. Nesse sentido, defendia-se, contra todo o descrédito, a importância de uma "sociologia histórica", sobretudo por uma razão em particular: os historiadores estavam, até então, tão preocupados com "os aspectos raros (unique), acidentais, episódicos e anedóticos da história política que eles tinham pouco a contribuir para a história das instituições culturais e sociais" (BARNES, 1972b, p. 29-55). Antes mesmo da publicação do primeiro número da revista francesa Annales, Barnes já intercedia a favor da relação multidisciplinar da história, citando, por exemplo, um dos próprios fundadores do periódico francês, Lucien Febvre, notadamente no uso da geografia para o exercício histórico. Outro ponto que cabe mencionar é a incorporação, para o trabalho historiográfico, da recusa de perspectivas racialistas, pelo menos no sentido do preconceito racial, para a compreensão dos processos de interação humana. Discorrendo sobre o "mito da raça" em 1925, o historiador americano afirmava ser muito curioso "que os críticos dessa monstruosidade [the racial phobia] raramente fizessem apelos sistemáticos para os fatos substânciais da história para refutar os argumentos de autores de Gobineau a Chamberlain e Grant" (BARNES, 1972c, p. 29-218).

A importância do contato de Freyre com essa geração de historiadores, além da ênfase notadamente social e cultural que se colocava, na tentativa de superação da predominância política e diplomática nos estudos históricos, e do deslocamento feito em relação à perspectiva racial, residia num aperfeiçoamento no trato com a documentação. Quanto ao primeiro caso, não são poucos os comentadores que enxergam em sua obra, de forma discutível é bem verdade, como um prenúncio ao movimento dos Annales (por exemplo, BURKE, 1997). Gustavo Tuna já mostrou com muita propriedade o papel decisivo da historiografia norte-americana na formação do pensamento histórico de Freyre. Isso já se fazia sentir desde os primeiros momentos após o término de seus estudos em Columbia. Além da dissertação ali defendida, uma passagem do diário explicita bem sua postura voltada para o social, rompendo com a história política "dos grandes homens": "há historiadores [...] que, na verdade, são simples estudiosos dos fatos chamados históricos. Ignoram 
as relações entre esses fatos: o principal. Mas assim simplistas, se julgam íntimos, ou senhores, de uma época. Isto só por terem reunido a respeito dessa época os fatos mortos como quem juntasse gravetos secos; e posto todos eles de pé e em fileira, dando a tudo isso alguma hierarquia e certos coloridos de pitorescos. É uma história, a organizada por esse processo, evidentemente superior à que se contenta com as datas e os nomes de reis e de generais. Mas o seu ar de suficiência, pelo fato de dominar fatos mortos, chega a ser comovente" (FREYRE, 1975, p. 100). Uma síntese do que chegou a realizar em $C G \mathcal{E} S$ já se encontrava nessa passagem. A preocupação de ir além dos fatos, interpretando a relação entre eles; a ênfase nos aspectos da intimidade sem, todavia, compreender o passado como um dado morto; o deslocamento da preocupação apenas com miudezas da erudição, como datas e nomes de pessoas importantes. Não seria preciso percorrer as páginas do livro de 1933 para corroborar o argumento. Em certa medida, o destaque feito à interpretação e a pouca importância dada aos aspectos cronológicos são usuais na tradição ensaística daquele momento (NICOLAZZI, 2008, p. 1-34).

O livro de Freyre é também uma espécie de "história filosófica" tal como concebida por alguns autores do oitocentos, através da qual um encadeamento lógico dos fatos era buscado em proveito de um sentido geral para a história narrada. Decorre dessa reflexão um outro ponto a ser comentado, a saber, o da já destacada fluidez cronológica no livro, que mistura dados oriundos de períodos diversos para sustentar determinados argumentos pontuais. A concepção tripartite e homogênea de tempo assumida por Gilberto lhe dava condições para tanto." Aqui cabe ressaltar também que a feição oral que o autor confere ao seu registro, como que querendo se aproximar da linguagem falada daqueles que são seus objetos de estudo, contribui nesse sentido: a oralidade no fluxo narrativo lhe permite mudanças em certo ponto aleatórias, não apenas de assuntos, mas também saltos importantes na cronologia. Mas é, de fato, por procurar entrever, através dos fatos mesmos, um sentido mais fundamental para a história da formação social Brasileira que Gilberto parece dar pouca atenção para a linearidade cronológica; afinal,

11 Freyre desenvolveu uma concepção particular de tempo tripartite, segundo a qual, para além de qualquer ruptura, o que fica evidente é a ligação íntima entre passado, presente e futuro. No prefácio à edição das suas memórias, escrito mais de quarenta anos depois da publicação de $C G \mathcal{E} S$, adverte a partir de um comentário sobre sua metodologia "saudosista" que sua forma de interpretação pretende dar conta, como um todo, "do passado-presente-futuro de um povo" (FREYRE, 1975, p. XII). 
sua história tinha por intenção menos traçar o correto encadeamento dos acontecimentos do que oferecer uma explicação plausível para os "problemas brasileiros", aquelas "questões seculares" que afligiam os de sua geração, sendo, entre todas elas, a miscigenação a que mais o inquietava (FREYRE, 1933, p. XII). Sua crítica a Varnhagen segue um pouco nesse sentido, quando o historiador sorocabano conjecturava sobre o sentido da história caso ela tivesse ocorrido por meio de pequenas propriedades, o que levaria a uma maior homogeneidade da população e reduziria as diferenças regionais entre todas as capitanias. O parecer de Freyre é extremamente direto: "Varnhagen é sempre de um simplismo infantil quando deixa a pura pesquisa historica, pela philosophia da historia" (FREYRE, 1933, p. 273, n. 2, itálico meu). Para Freyre, havia uma diferença sensível entre a erudição e a filosofia, entre a pesquisa pura dos fatos e a sua interpretação filosófica.

Ou seja, a conjectura que se pode levantar sobre as diferenças entre a escrita ensaística e a praxe historiográfica tradicional, isto é, entre síntese sociológica e erudição crítica, encontra também um amparo na maneira como Freyre usou do gênero. ${ }^{12}$ Alguns autores já haviam percebido essa distância. Para ficar apenas num único exemplo, dada sua significância para este estudo, José Lins do Rêgo, na preparação de terreno que antecedeu a publicação de $C G \mathcal{E} S$, salienta de forma irônica que "a história do Brasil deixou de ser em suas mãos [nas de Freyre] uma vaidade de saber mais datas que os outros como se dá com o Barão do Rio Branco, ou um puro deleite de esquisito como foi para Capistrano de Abreu, o homem que poderia ter sido o nosso grande historiador se não tivesse querido ser somente o nosso maior esquisitão. A história que Gilberto Freyre sabe e escreve tem mais uma expressão de vida que de pura memória. É uma história com sangue, mais humana do que sábia”. Em seguida considera que "a obra que Capistrano não quis concluir é esta que Gilberto Freyre vai começar” (José Lins do Rego, em FONSECA, 1985, p. 40-41). Pois bem, ao autor de Apipucos, no entender de Zélins,

12 Oliveira Vianna e Manoel Bomfim são dos autores que permitem sustentar essa conjectura. No prefácio de seu Populações merdionaes do Brazil, o escritor fluminense teceu a seguinte colocação: "no estado actual da sciencia historica, o texto dos documentos não basta só por si para fazer reviver uma epoca, ou comprehender a evolução particular de um dado aggregado humano [...]" (VIANNA, 1920, p. II-III). Idéia semelhante fora colocada por Bomfim alguns anos antes: no estudo da história pátria, de seus acontecimentos fundadores e "para destacar-lhes a feição geral, o pensamento não se perderá nos desvãos da erudição, nem dispensará energias para effeitos sómente litterarios" (BOMFIM, 1929, p. 8). 
não faltará nem espírito plástico nem simpático para a tarefa; assumindo explicitamente a idéia de ensaio sócio-histórico para seu trabalho, Freyre passará a figurar-se como nome paradigmático do gênero no Brasil.

Mas não é por causa disso que Gilberto foi menos atento às necessidades do método. Aqui reside a grande diferença que o torna singular diante dos nomes de Bomfim, Vianna e Caio Prado Jr. (pelo menos na época do Evolução política do Brasil): Freyre frequentava arquivos e reconhecia a importância do recurso às primary sources para a escrita da história. Isto é, em $C G \mathcal{E} S$, erudição histórica e história filosófica parecem encontrar um terreno comum de existência, sem que um dos pares necessite ser elidido em proveito do outro. São muitas em seu diário as passagens que tocam num ponto que, sendo parte epistemológica do método dos historiadores, é sem dúvida um fundamento considerável de seu métier: aquilo que Arlette Farge já definiu como um "gosto pelos arquivos" (FARGE, 1989). Em sua viagem pelos Estados Unidos, teve a oportunidade de frequentar a famosa biblioteca do congresso, sobretudo a seção dos manuscritos: "tenho agora o direito de tocar em papéis virgens, lê-los, estudá-los, copiá-los”, anotou para o ano de 1922. Já na realidade tropical, embora as condições tenham consideravelmente mudado, a frequência a tais lugares permanece: "continuo a frequentar a imunda Biblioteca Pública daqui e a tomar notas. Passo lá tardes inteiras. Tem alguns mss preciosos. Muita coisa estragada. Paranhos me prometeu reunir restos de arquivos de engenhos velhos. Estou interessado em cartas, inventários, testamentos. Documentos menos públicos e mais íntimos. Já consegui reunir da família alguma coisa" (FREYRE, 1975, p. 71 e 135). Mesmo arquivos policiais faziam parte do roteiro de suas pesquisas pessoais.

Em 1935, Freyre ressalta seu penoso trabalho de erudição em carta a José Lins: "esses livros 'de erudição e pesquisa', a que os belletristas se referem sempre com tanto desdém, dão um trabalho horrível, não só físico - do que já devia se queixar o meu saudoso predecessor Pereira da Costa - como propriamente intelectual, pelo esforço de articular, interpretar e tentar esclarecer material tão confuso" (citado em GIUCCI; LARRETA, 2007, p. 572). ${ }^{13}$ No ano anterior, em conferência à Faculdade

13 Francisco Augusto Pereira da Costa (1851-1923), egresso da Faculdade de Direito de Recife, depois de ter atuado no jornalismo durante a década de 1870, foi fundador da Academia Pernambucana de Letras e membro do Instituto Arqueológico, Histórico e Geográfico de Pernambuco. Foi autor, entre outras obras de pesquisa, dos Anais pernambucanos, dez volumes que cobrem o período entre 1493 e 1850. 
de Recife, remontou aos seus anos de estudante de história em Columbia, ressaltando "o estudo das ciências sociais nas universidades americanas", onde notava a "insistência que se faz em todo o estudo universitário de ciências sociais nos Estados Unidos, inclusive no de direito, na familiaridade do estudante com as fontes, ou as chamadas "primary sources' de cada especialização". Para ele, o recurso à documentação primária tinha por intenção "evitar a repetição de erros colhidos às vezes de segunda e terceira mão" (ARAÚJO, 2005, p. 194). A consulta de "papéis virgens" era, portanto, requisito incontornável na tarefa de representar o passado brasileiro.

As fontes provam e Gilberto Freyre levava isso em consideração. Parte de suas discordâncias em relação a alguns argumentos de Euclides da Cunha era pautada diretamente sobre documentos que lhe garantiam a legitimidade para oferecer outros argumentos. No uso dos relatos de viajantes, fontes privilegiadas em $C G \mathcal{E S}$, há inclusive critérios de escolha que recortam aqueles merecedores de fé daqueles que deveriam ser lidos "como se lê um romance". Outro momento revelador é a retificação feita de Oliveira Vianna, onde se percebe uma distinção importante entre pesquisa documental e ornamentos literários. "As generalizações do professor Oliveira Vianna, que nos pintou com tão bonitas côres uma população paulista de grandes proprietarios e opulentos fidalgos rusticos, teem sido ultimamente rectificadas, naquelles seus falsos dourados $e$ azues, por investigadores mais realistas e melhor documentados que o illustre sociologo" (FREYRE, 1933, p. 66-67).

Esses são apenas alguns dos indícios que demonstram o trabalho de erudição realizado por Freyre, o que o distinguia sobremaneira dos outros ensaístas mencionados, e mesmo de Paulo Prado, dentre todos o que mais perto disso chegou, ainda que com um uso bastante livre dos documentos por ele consultados. Gilberto Freyre se valeu largamente das fontes de arquivo, mesmo se ele não as citava tão frequentemente, incorporando-as, sem as devidas referências, à sua própria linguagem. Thomas Skidmore chamou a atenção para isso, afirmando que "não deveria ser surpresa que a sua maneira de lidar com a evidência não seja a da história ortodoxa [...] Freyre cita muitas evidências contemporâneas, mas quase nunca compartilha com o leitor como a sua análise da evidência o levou às suas conclusões [...] Além de seu uso inconsequente de evidências científicas, Freyre tem o hábito de afirmar como dados argumentos para os quais as provas citadas são fracas ou inexistentes". Em seguida, o brasilianista chega a uma explicação talvez pouco adequada. As razões para a boa acolhida do livro, a despeito de tais inconseqüências 
metodológicas, residiriam no fato de que "os padrões para aquele tipo de prosa no Brasil dos anos 30 eram menos exigentes em termos de provas, e seus contemporâneos não levantaram isto como crítica importante" (SKIDMORE, 2003, p. 54-55). Esse tipo de prosa, aqui entendido como ensaio histórico, talvez não levasse a uma ausência de exigências de ordem metodológicas, como quer o autor, mas certamente demandava exigências distintas. Não seria o caso de pensar que para essa tradição ensaística o lugar da comprovação estaria menos nos documentos do que naquele que os leu e pesquisou? Não seria essa, ainda, a razão para a ausência de inúmeras referências em $C G \mathcal{E} S$, já que o autor ocupava o lugar da fonte por excelência?

Skidmore reconhece que Freyre organiza seu material à maneira dos autores de ficção. É bem verdade, como se sabe, que no livro há como que uma pletora literária, um excesso de elementos tomados, quem sabe, da imaginação do autor que conferem à sua prosa as reconhecidas feições poéticas que não poucos leitores mencionaram. Desde as índias a pentear os cabelos nas águas de algum riacho ou outras a abrir as pernas para colonos "gulosos de mulher" à sombra de frondosos cajueiros, até senhores brancos, estirados dentro de uma rede preguiçosos, "palitando os dentes, fumando charutos, cuspindo no chão, arrotando alto, peidando, deixando-se abanar, agradar e catar piolho pelas mulequinhas, coçando os pés ou a genitalia: uns coçando-se por vicio; outros por doença venerea ou da pelle" (FREYRE, 1933, p. 468). Essa última descrição não é apenas uma provocação à visão pomposa que Oliveira Vianna criou para a aristocracia colonial, fazendo os nobres e altivos senhores do Populações meridionaes descer aos limites da fisiologia onde se igualam a plebeus; ela é também um exemplo contundente daquela pletora, do passo a mais que Freyre constantemente dava, beirando o lado da ficção e sob o risco de criar no leitor a sensação mencionada por Darcy Ribeiro, de que se "engambelava" ao ler aquele ensaio (RIBEIRO, 200o). Para Freyre, não bastava simplesmente descrever o real tal como ele se dava ao olhar; era preciso colocar nele uma dose extra de realidade, fazendo dele um "mais real que o real”, como escreveu certa vez. Pode-se pensar que, embora pautado em fontes, seu texto era construído como que à revelia delas, fazendo-as dizer algo a mais, algo que não estava contido nelas, mas que, por meio de uma linguagem hábil, era possível devolver-lhes uma certa dose de experiência. $\mathrm{O}$ autor, nesse sentido, assume o primeiro plano nessa tarefa representativa.

Por isso parece ser reducionista a maneira como os biógrafos de Freyre elaboraram a questão, ao afirmar que a obra do sociólogo, assim 
como a de Caio Prado Jr., marcariam a "passagem do ensaísmo à pesquisa empírica” (GIUCCI; LARRETA, 2007, p. 433). ${ }^{14}$ O próprio livro de Freyre contradiz essa suposta passagem, já que ensaio e pesquisa fazem parte de um mesmo procedimento, o que parece negar, inclusive, outra passagem retirada de sua biografia: a que declara "sua posição ao mesmo tempo de escritor e de cientista social, oposto tanto ao estreito profissionalismo acadêmico quanto às facilidades do ensaísmo".

Enfim, Gilberto Freyre escreveu CGES na forma de um ensaio e como quem pratica um certo tipo de heresia. Ele não estava nem plenamente lá, nem totalmente aqui; não assumia todos os requisitos demandados para a historiografia propriamente dita, tampouco se rendeu apenas às peripécias estetizantes da linguagem. Ao mesmo tempo, contestava o empirismo que culminava numa erudição pedante e inútil, e criticava a ornamentação retórica desvencilhada de qualquer contato com a realidade. Escreveu um ensaio da maneira como Theodor Adorno o definiu, quando insinuou que este gênero tão particular obedece a uma única regra, a regra da altercação: "é por isso que a lei formal mais profunda do ensaio é a heresia. Apenas a infração à ortodoxia do pensamento torna visível, na coisa, aquilo que a finalidade objetiva da ortodoxia procurava, secretamente, manter invisível" (ADORNO, 2003, p. 45). As virtudes do herege são, portanto, justamente expandir as possibilidades da escrita da história nacional, não apenas oferecendo um novo modelo interpretativo, mas também apresentando um outro estilo de história.

\section{REFERÊNCIAS BIBLIOGRÁFICAS}

ADORNO, Theodor W. “O ensaio como forma”. In: Notas de literatura I. São Paulo: Duas Cidades; Ed. 34, 2003.

ANDRADE, Mário. “A escrava que não é Isaura (discurso sobre algumas tendências da poesia modernista)”. In: Obra imatura. São Paulo: Martins, 1960.

. "Prefácio interessantíssimo". In: Poesias completas. 3ª edição. São Paulo: Martins; Brasília: INL, 1972.

ARAÚJO, Ricardo Benzaquen de. Guerra e paz. Casa-grande E senzala e a obra de Gilberto Freyre nos anos 30. 2ạ. edição. São Paulo: Editora 34, 2005.

14 Os autores ali fazem referência ao artigo de BASTOS, (1989, p. 335-346), embora a autora não utilize tais termos, até mesmo porquê, o artigo versa sobre o livro de 1933 de Caio Prado, em que há muito de ensaio e pouco de "pesquisa empírica". O que ela chama a atenção, de fato, é a oposição das perspectivas de cada um dos autores. 
AZEVÊDO, Neroaldo Pontes. Modernismo e regionalismo. Os anos 20 em Pernambuco. João Pessoa: Secretaria de Educação e Cultura da Paraíba, 1984.

BARNES, Harry Elmer. "Recent historical tendencies". In: History and social intelligence. New York: The Revisionist Press, 1972a.

. "The newest history”. In: History and social intelligence. New York: The Revisionist Press, 1972 b.

. "The race myth". In: History and social intelligence. New York: The Revisionist Press, 1972c.

BASTOS, Elide Rugai. “A sociologia nos anos 3o. Uma revisão crítica da articulação: raça e cultura”. In: D'INCAO, Maria Angela (org.). História e ideal. Ensaios sobre Caio Prado Júnior. São Paulo: Unesp; Brasiliense, 1989.

BLANCKAERT, Claude. “18oo - Le moment 'naturaliste' des sciences de l'homme”. In: Revue d'Histoire des Sciences Humaines, n’. 3, 2000.

- La nature de la société. Organicisme et sciences sociales au XIXe siècle. Paris: L'Harmattan, 2004.

BOMFIM, Manoel. O Brazil na America. Caracterização da formação brazileira. Rio de Janeiro: Livraria Francisco Alves, 1929.

BRAUDEL, Fernand. “À travers un continent d'histoire. Le Brésil et l'ouvre de Gilberto Freyre”. In : FREYRE, Gilberto. Casa-grande E senzala. Edição crítica coordenada por Guillermo Giucci, Enrique Rodríguez Larreta e Edson Nery da Fonseca. Paris: ALLCA XX, 2002.

BURKE, Peter. “Gilberto Freyre e a nova história”. In: Tempo Social. São Paulo, v. 9, № 2, 1997.

CANDIDO, Antonio. “A revolução de 1930 e a cultura”. In: A educação pela noite e outros ensaios. São Paulo: Ática, 1989.

. "Literatura e cultura de 1900 a 1945 ". In: Literatura e sociedade. São Paulo: T. A. Queiroz, 2000.

CASTELLO, José Aderaldo. José Lins do Rêgo: modernismo e regionalismo. São Paulo: Edart, 1961.

CERTEAU, Michel de. "L'histoire, science et fiction". In: Histoire et Psychanalyse entre science et fiction. Paris: Gallimard, 2002.

CEZAR, Temístocles. "A retórica da nacionalidade de Varnhagen e o mundo antigo: o caso da origem dos tupis”. In: GUIMARÃES, Manoel Luiz Salgado. Estudos sobre a escrita da história. Rio de Janeiro: 7 Letras, 2006.

CORRÊA, Roberto Alvim. "Gilberto Freyre ensaísta”. In: GILBERTO FREYRE: sua ciência, sua filosofia, sua arte. Ensaios sôbre o autor de Casagrande E senzala e sua influência na moderna cultura do Brasil, comemorativos do 25a aniversário da publicação dêsse seu livro. Rio de Janeiro: José Olympio, 1962. 
D’ANDREA, Moema Selma. A tradição re(des)coberta. O pensamento de Gilberto Freyre no contexto das manifestações culturais e/ou literárias nordestinas. Campinas: Editora da Unicamp, 1992.

DIMAS, Antonio. “Barco de proa dupla: Gilberto Freyre e Mário de Andrade”. In: FREYRE, Gilberto. Casa-grande E senzala. Edição crítica coordenada por Guillermo Giucci, Enrique Rodríguez Larreta e Edson Nery da Fonseca. Paris: ALLCA XX, 2002.

FALCÃO, Vânia L. S. de Barros. Casa-grande E senzala: um espaço textual de tramas e confluências. Tese de doutorado em Letras. Porto Alegre: UFRGS, 2003.

FARGE, Arlette. Le goût de l'archive. Paris: Éditions du Seuil, 1989.

FONSECA, Edson Nery da. "Casa-grande \& senzala como obra literária”. In: FREYRE, Gilberto. Casa-grande \& senzala. Edição crítica coordenada por Guillermo Giucci, Enrique Rodríguez Larreta e Edson Nery da Fonseca. Paris: ALLCA XX, 2002. . (org.) Casa-grande E senzala e a crítica brasileira de 1933 a 1944. Artigos reunidos e comentados por Edson Nery da Fonseca. Recife: Companhia Editora de Pernambuco, 1985 .

FREYRE, Gilberto. Casa-grande E senzala. Formação da familia brasileira sob o regimen de economia patriarchal. Rio de Janeiro: Maia \& Schimidt Ltda, 1933.

. Tempo morto e outros tempos. Trechos de um diário de adolescência e primeira mocidade, 1915-1930. Rio de Janeiro: José Olympio, 1975.

. "Como e porque escrevi Casa-grande E senzala". In: FREYRE, Gilberto. Casa-grande E senzala. Edição crítica coordenada por Guillermo Giucci, Enrique Rodríguez Larreta e Edson Nery da Fonseca. Paris: ALLCA XX, 2002.

GAIO, André Moysés. Modernismo e ensaio histórico. São Paulo: Cortez, 2004.

GIUCCI, Guillermo; LARRETA, Enrique Rodríguez. Gilberto Freyre uma biografia cultural. A formação de um intelectual brasileiro: 1900-1936. Rio de Janeiro: Civilização Brasileira, 2007.

HARTOG, François. “Michelet, la vie, l'histoire”. In: Évidence de l'histoire. Ce que voient les historiens. Paris: Éditions EHESS, 2005.

LAFETÁ, João Luiz. 1930: a crítica e o modernismo. São Paulo: Duas Cidades, 1974.

LAPA José Roberto do Amaral. “O modernismo e a historiografia”. In: Historiografia brasileira contemporânea (a história em questão). Petrópolis: Vozes, 1981.

LIMA, Luiz Costa. “A versão solar do patriarcalismo: Casa-grande \& senzala”. In: A aguarrás do tempo. Estudos sobre a narrativa. Rio de Janeiro: Rocco, 1989.

MACÉ, Marielle. "Mémoire du genre”. In: Le temps de l'essai. Histoire d'un genre en France au XXe siècle. Tours: Belin, 2006. 
MARTIUS, Carlos Frederico Ph. de. "Como se deveescrever a historia do Brasil. Dissertação offerecida ao Instituto Historico e Geographico do Brasil, pelo Dr. Carlos Frederico Ph. de Martius. Acompanhada de uma Bibliotheca Brasileira, ou lista das obras pertencentes á Historia do Brasil”. In: RIHGB, tomo 6, 1866.

MEUCCI, Simone. Gilberto Freyre e a sociologia no Brasil: da sistematização à constituição do campo científico. Tese de doutorado em Sociologia. Campinas: Unicamp, 2006.

MOISÉS, Massaud. “Ensaio”. Dicionário de termos literários. São Paulo: Cultrix, 1974.

MORAES, Eduardo Jardim de. "Modernismo revisitado". Estudos Históricos, vol. 1, n. 2, 1988.

NICOLAZZI, Fernando. Um estilo de história: a viagem, a memória, o ensaio. Sobre Casagrande \& senzala e a representação do passado. Tese em história. Porto Alegre: UFRGS, 2008.

. "À sombra de um mestre. Gilberto Freyre leitor de Euclides da Cunha”. In: História (UNESP), v.29, 2010.

. "Representação e distância: naturalismo, linguagem e alteridade na escrita de Os sertões”. In: NICOLAZZI, Fernando; PEREIRA, Mateus Henrique de Faria; SILVA, Ana Rosa Cloclet. Estudos de história da historiografia brasileira. São Paulo: Hucitec; Fapemig (no prelo).

NOVICK, Peter. That noble dream. The "objectivity question" and the American historical profession. Cambridge University Press, 1998.

PALLARES-BURKE, Maria Lúcia Garcia. “O caminho para a casa-grande: Gilberto Freyre e suas leituras inglesas”. In: FREYRE, Gilberto. Casa-grande E senzala. Edição crítica coordenada por Guillermo Giucci, Enrique Rodríguez Larreta e Edson Nery da Fonseca. Paris: ALLCA XX, 2002. . Gilberto Freyre. Um vitoriano nos trópicos. São Paulo: Editora UNESP, 2005.

RIBEIRO, Darcy. “Gilberto Freyre. Uma introdução a Casa-grande \& senzala”. In: FREYRE, Gilberto. Casa-grande E senzala. 39ª. edição. Rio de Janeiro: Record, 2000.

ROCHA, João Cezar de Castro. "Notas para uma futura pesquisa: Gilberto Freyre e a Escola Paulista”. In: FALCÃO, Joaquim; ARAÚJO, Rosa Maria Barboza (orgs.). O imperador das idéias. Gilberto Freyre em questão. Rio de Janeiro: Topbooks, 2001. . "Uma curiosa hermenêutica". In: O exílio do homem cordial. Rio de Janeiro: Museu da República, 2004.

RODRIGUES, Francisco José. “Casa-grande \& senzala: ensaio e estilo”. Ciência E Trópico, vol. 2, n. 2, jul/dez., p. 233-247, 1974.

RODRIGUES, José Honório. Teoria da história do Brasil (Introdução metodológica). 3a․ edição. São Paulo: Companhia Editora Nacional, 1969.

SEVCENKO, Nicolau. "Transformações da linguagem e advento da cultura modernista no Brasil”. In: Estudos Históricos, vol. 6, n. 11, 1993. 
SKIDMORE, Thomas. "Raízes de Gilberto Freyre”. In: KOSMINSKY, Ethel et alli (orgs.). Gilberto Freyre em quatro tempos. Bauru: EDUSC, 2003.

STAROBINSKI, Jean. “Peut-on définir l'essai?”. In: Pour un temps/Jean Starobinski. Paris: Centre Georges Pompidou, 1985.

TUNA, Gustavo Henrique. Viagens e viajantes em Gilberto Freyre. Dissertação de mestrado em história. Campinas: Unicamp, 2003.

VENTURA, Roberto. "Sexo na senzala: Casa-grande $\mathcal{E}$ senzala entre o ensaio e a autobiografia”. Literatura e sociedade, n. 6, p. 212-223, 2001/2.

VERÍSSIMO, José. “O modernismo”. In: Revista do Brasil, anno I, vol. I, 1916.

VIANNA, F. J. Oliveira. Populações merdionaes do Brazil (historia - organisação - psycologia). Primeiro volume. Populações ruraes do centro-sul (paulistas - fluminenses - mineiros). São Paulo: Monteiro Lobato \& Cia. Editores, 1920.

VICENTE, Silvana Moreli. "Entre o inferno e o paraíso: o ensaio de Gilberto Freyre". Estudos Linguísticos, XXXIV, p. 680-685, 2005.

WEBER, Max. "L'objectivité de la connaissance dans les sciences et la politique sociales". In: Essais sur la théorie de la science. Paris: Plon, 1965.

ZACH, Nathan. "Imagism and vorticism”. In: BRADBURY, Malcolm; McFARLANE, James. Modernism. 1890-1930. New York: Penguin Books, 1976. 